\title{
Research on Observation of Settlement Deformation of Zhengzhou-Jinan High-speed Railway and Information Platform of Observation Data
}

\author{
Ni Xiuyong ${ }^{1 *}$ \\ ${ }^{1}$ Shandong transport vocational college, TAIAN, SHANDONG, 271000, China
}

\begin{abstract}
In order to provide data support for engineering construction, this paper proposes to study the construction of information platform of settlement deformation observation data. In this paper, the information platform for observation data is established based on the settlement deformation data of Zhengzhou-Jinan high-speed railway. The results show that the settlement deformation observation platform in this paper can effectively integrate the data and ensure the accuracy of the data. This paper sets an example for the future research on the construction of information platform of high-speed railway settlement.
\end{abstract}

\section{Background Introduction}

High-speed railway, as an important sign of modernization and globalization of a country, has become one of the important guarantees for long-distance travel and convenient logistics of the country because of its characteristics of high speed, convenience and environmental protection. However, there are many inevitable problems in the construction and running process of high-speed railways, such as the settlement of high-speed railways ${ }^{[1]}$.

The settlement of high-speed railways is mainly caused by the settlement of high-speed railway foundation and natural foundation. First of all, just like an ordinary train, the subgrade of high-speed railway is mainly made of materials such as stone, soil and concrete. As a result, there are certain voids and pores among the particles of materials. Moreover, because both the subgrade fill and the underlying foundation are elastic-plastic materials, the pores between the subgrade fill particles will be compressed due to the influence of the gravity and dynamic stress of the train after the high-speed railway passes through, and the soil will undergo plastic deformation, which cannot be recovered without external force. This also leads to the settlement of the whole high-speed railway foundation, making the surface of the train track uneven. Besides, the water body in the underlying layer will become unstable under the compressional force, which will lead to foundation settlement. When the high-speed railway runs to this position at high speed, it is prone to accidents ${ }^{[2]}$.

Therefore, it is necessary to monitor the settlement of high-speed railway foundation in real time, so that the potential danger can be investigated in time. Once settlement occurs, it will be calculated immediately. If the settlement affects the normal field operation during the construction period or endangers the normal operation of trains, a warning will be issued immediately. Therefore, settlement analysis not only provides an effective and real-time guarantee for the later construction of non-ballast track, but also accumulates valuable experience for future construction under similar topographic and geological conditions. At present, the settlement monitoring of China's high-speed railway during construction, due to its long project period, high precision, large amount of data generated, and lack of professional system support and analysis, faces many difficulties such as untimely feedback, low acceptability of the construction side, and high labor cost, which is inconsistent with the strategic goal of building big data in China. Therefore, it has become a top priority to enhance the informationization and automation of settlement monitoring ${ }^{[3]}$.

In view of the above-mentioned problems, this paper proposes to study the observation of settlement deformation and the construction of observation data information platform. The information platform model is established, and its system framework and database have been designed. Based on the practical application scenario of settlement deformation of Zhengzhou-Jinan high-speed railway, the information platform suitable for settlement deformation data and observation data of Zhengzhou-Jinan high-speed railway is established. The data analysis technology is applied to the information platform, thus providing theoretical guidance for the automation and information construction of settlement deformation observation and evaluation of high-speed railway track.

\footnotetext{
*Corresponding author: nixiuyong@sina.com
} 


\section{Settlement Deformation Observation and Data Information Platform Construction}

\subsection{Theoretical Basis of Settlement Deformation Observation}

\section{(1) Leveling}

According to the settlement and foundation characteristics of Zhengzhou-Jinan high-speed railway, this paper adopts the combination of regional first-order leveling network (supplemented by second-order), high-precision leveling network along the line and scalar network set on the rail track to monitor the characteristics of deformation of various sizes. The regional leveling network is used to draw the surface deformation map, the high-precision leveling network along the railway track is used to monitor the track deformation and slope change caused by settlement, and the scalar network is set to measure the differential settlement between bridge piers and abutments, and the comfort change of high-speed railway ${ }^{[4]}$.

\section{(2) Time series interferometry}

Traditional differential interferometry is easily affected by complex natural environment, so the time series interferometry method is proposed, that is, the high coherent point in time series interferometry is used as the basis for time series measurement, tracks and natural factors such as atmospheric delay are analyzed, and data are adjusted to reduce errors, so as to obtain the final deformation phase information.

\section{(3) Groundwater level monitoring}

The main drivers of surface settlement could be found out through this method, which carries out qualitative and quantitative analysis on the deformation characteristics of underground aquifers when encountering water. The groundwater level determines how to formulate the surface settlement plan and the train system operation plan in the near future. ${ }^{[5]}$.

\section{(4) Borehole extensometer monitoring}

Borehole extensometer is the primary means for early warning of foundation aquifer monitoring, which is of great help for understanding hydrological conditions, hydraulic and deformation characteristics at various depths.

\subsection{Field observation and real-time monitoring instruments for settlement deformation}

\section{(1) Monitoring section}

The fifth work area is selected for the observation of engineering settlement deformation. The fifth branch of ZJTLSG-2 bid section of the newly-built Zhengzhou-Jinan Railway project is located in Dongchangfu District, Liaocheng City, Shandong Province. The line passes through areas such as Yansi Street, Daokoupu Street, and Houying Town from east to west. The range of the main line is between DK109+179.16 (905 \# pier on the left line of Chiping Bridge) and DK119+508.91 (spanning Jinan abutment on the left line of 316 Bridge), and the length of the main line is $9.94 \mathrm{~km}$, including the bridge length of $7.117 \mathrm{~km}$, the station length of $2.71 \mathrm{~km}$ and the section subgrade of $0.11 \mathrm{~km}$

\section{(2) Monitoring instruments and equipment}

The working principle, application scope, precision requirements, durability and other characteristics of various automatic monitoring elements are measured, and the monitoring instruments to be used are selected considering the monitoring requirements of each section $^{[6]}$.

a.Subgrade settlement: The settlement of the foundation needs to be tested, and mainly measured by single-point settlement meter. The instrument is set in the foundation, with precision leveling used as the verification method, and settlement plate used as the verification measuring point.

Newly built Zhengzhou-Jinan railway (Shandong section) ZJTLSG-2 section, the fifth branch

Table 1 settlement observation

\begin{tabular}{|c|c|c|c|}
\hline \multicolumn{4}{|c|}{ Settlement observation badge } \\
\hline $\begin{array}{c}\text { Measuring } \\
\text { point range }\end{array}$ & DK117+070 & $\begin{array}{c}\text { Measuring } \\
\text { points } \\
\text { number }\end{array}$ & 0117070B1 \\
\hline $\begin{array}{c}\text { Measuring } \\
\text { engineer }\end{array}$ & Song Faxin & $\begin{array}{c}\text { Telephone } \\
\text { number }\end{array}$ & \\
\hline $\begin{array}{c}\text { Professional } \\
\text { Engineer }\end{array}$ & Jia Weidong & $\begin{array}{c}\text { Telephone } \\
\text { number }\end{array}$ & \\
\hline
\end{tabular}

Subgrade settlement plate, pay attention to protection

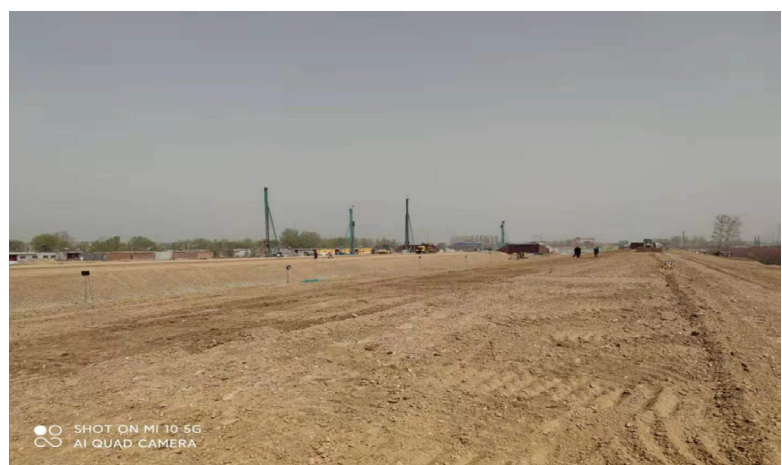

Picture 1 Settlement detection device 


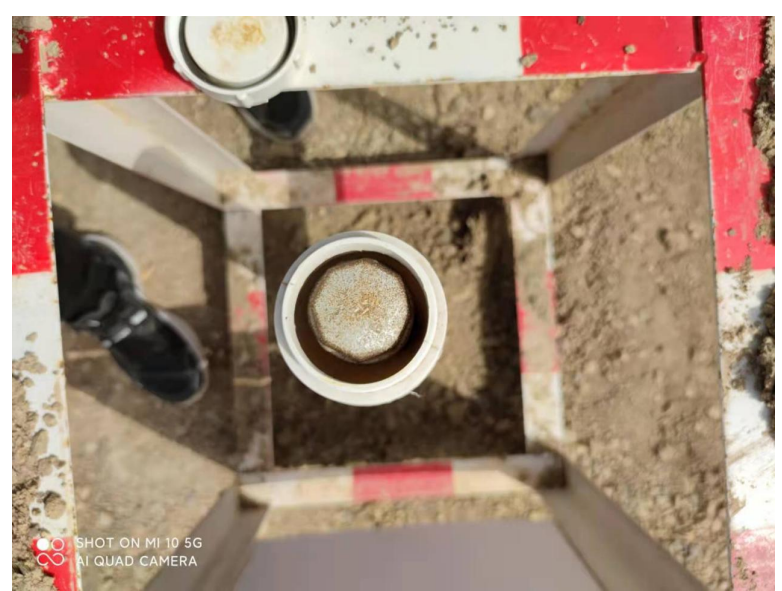

Picture 2 Settlement detection device

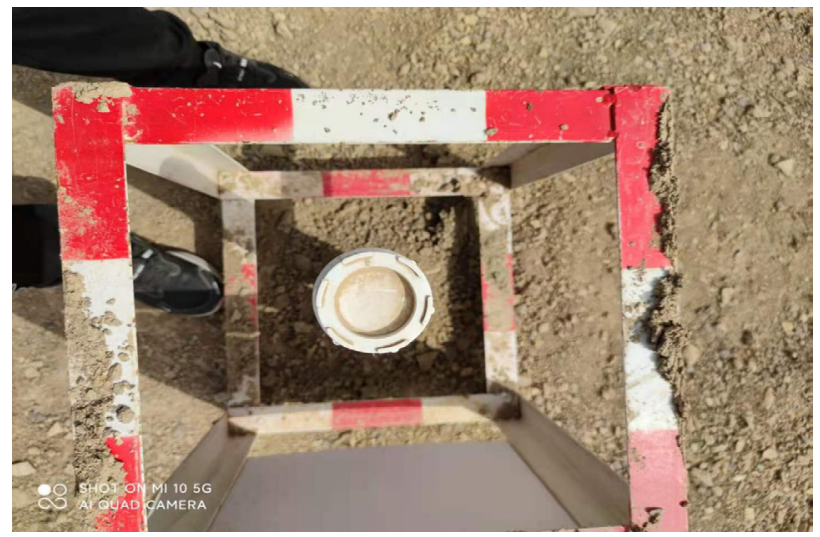

Picture 3 Settlement detection device

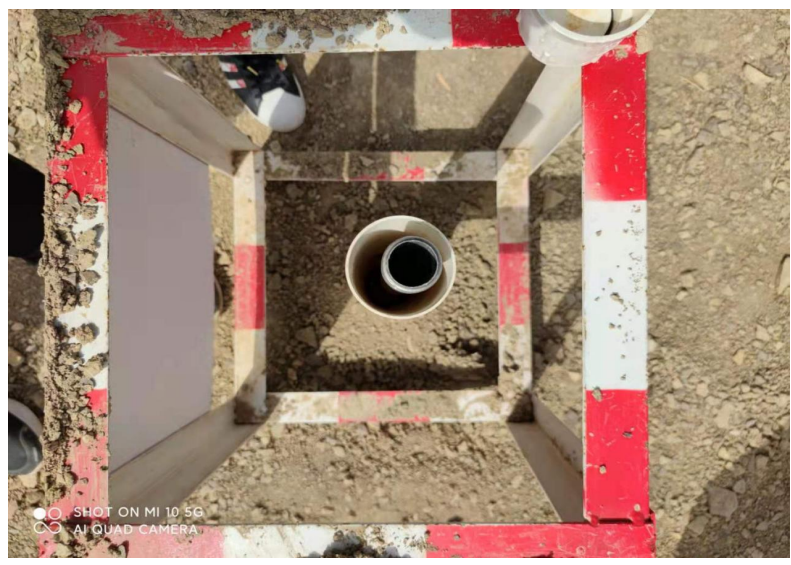

A device for detecting single point settlement on high-speed railway subgrade

b. Bridge settlement: The settlement of the foundation needs to be tested, and is mainly measured by hydrostatic leveling. The instrument is put in the beam end, with precision leveling used as the verification method, and pier measuring point used as the verification measuring point.

c. Settlement of transition section: the settlement of foundation and post construction differential settlement need to be tested. Foundation settlement is mainly measured by a single-point settlement meter. The instrument is set in the foundation, with precision leveling used as the verification method, and settlement plate used as the verification measuring point. However, the post construction differential settlement is mainly measured by electric level ruler and high-speed railway differential settlement monitor. The instruments are set in the side of concrete cushion, with electrical level ruler and single-point settlement meter used as verification methods, and multiple measuring points with certain intervals used for verification ${ }^{[7]}$.

\section{(3) Instrument layout}

a. Location selection of electrical level ruler: It is generally used to monitor the differential settlement of subgrade in transition section. With the application of traditional methods, it was finally decided to place the electrical level rulers on the subgrade of the transition section every 20 meters. The cross-sectional diagram of the specific placement location is shown in Figure 1 below.

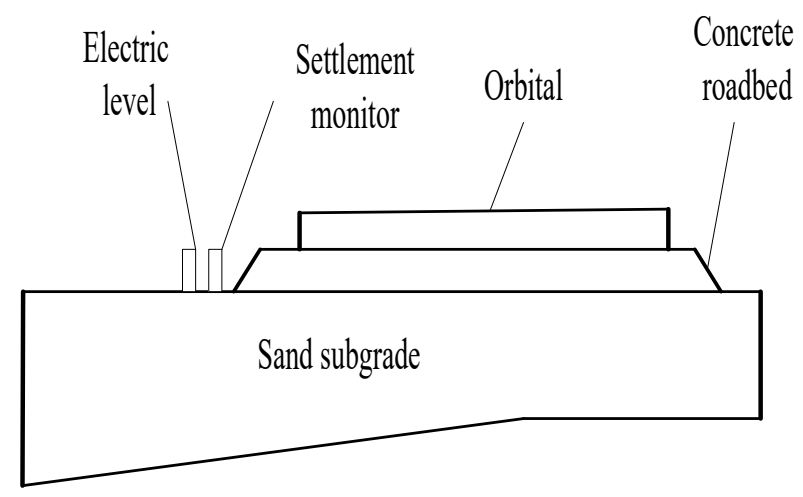

Figure 1 Cross-sectional Diagram of the Placement Location

The electrical level ruler is placed outside the subgrade surface of the railway track, $10 \mathrm{~cm}$ away from the edge.

b. Location selection of high-speed railway differential settlement monitors: they are arranged on the same side as the electrical level ruler every 20 meters.

c. Location selection of single-point settlement meter: The distance between two single-point settlement meters is $100 \mathrm{~m}$, and the placement location is shown in Figure 2 below.

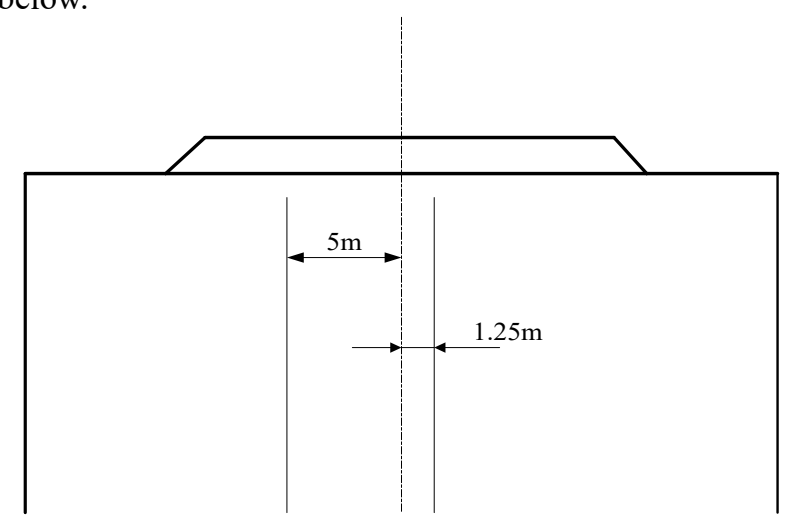

Figure 2 Cross-sectional Diagram of Placement Location

Two settlement measuring points need to be selected. The settlement measuring point of the railway central line 
should be on the left side of the central line, which is $1.25 \mathrm{~m}$ away from it, while the other measuring point should be on the other side of the central line, which is $5 \mathrm{~m}$ away from it. Both measuring points should be at the center of prestressed pipe pile.

\section{(4) Connection of monitoring instruments}

There are two ways of connecting monitoring instruments: bus type and branch type. When installing a large number of similar components continuously, bus connection method is often used, which is simple and space-saving. By connecting multiple components in series, they can be simply connected to the acquisition module through the bus module. It is simple and convenient, and can save cables and space. When the components are few, of various types or relatively scattered, the branch connection method is usually used. These components are respectively connected to the acquisition module using RS485 shielded cable tracks. These components do not affect each other. According to the realities of Zhengzhou-Jinan high-speed railway, the bus type is selected for the electrical level ruler and the high-speed railway differential monitor and branch type is selected for single-point settlement meter and single-point sedimentation meter ${ }^{[8]}$.

\subsection{Information Platform System for Observation Data}

\section{(1) System development platform and software and hardware environment}

The system architecture design platform uses Visio, the application software development platform uses Visio Studio 2019, the GIS (Geographic Information System) software development platform uses ArcGIS platform, the spatial database platform uses Geodatabase platform to establish data models, and the programming language uses C\#.

GIS platform settings use desktop 10 and ArcGISRuntime 10 or ArcGIS for basic data processing. The database platform uses Geodatabase to store and manage various basic data. The operating system uses Windows 7 or Windows 10. Net Framework 3.5, Microsoft, Excel, and Txt are used to provide an object-oriented programming environment and input or output some simple documents. In terms of hardware, a PC server is used for GIS server and development, and a minicomputer is used for database server.

\section{(2) System design}

The design steps of the system are shown in Figure 3 below.

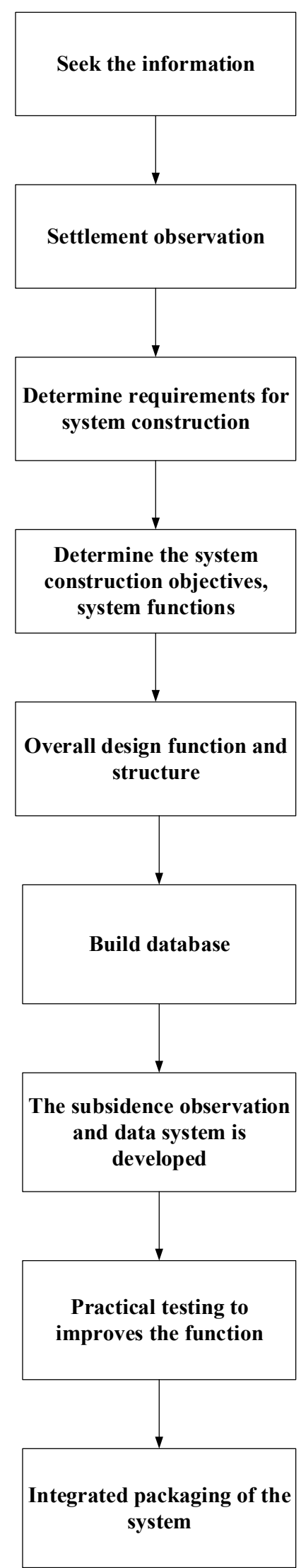

Figure 3 Design Steps of the System

The logical structure of the system is based on the ArcGIS Engine platform, and adopts the $\mathrm{C} / \mathrm{S}$ (Client/Server) architecture to connect the client with the server and the database. The system is divided into four 
layers: data layer, service layer, application layer and user layer. Its structure diagram is shown in Figure 4 below.

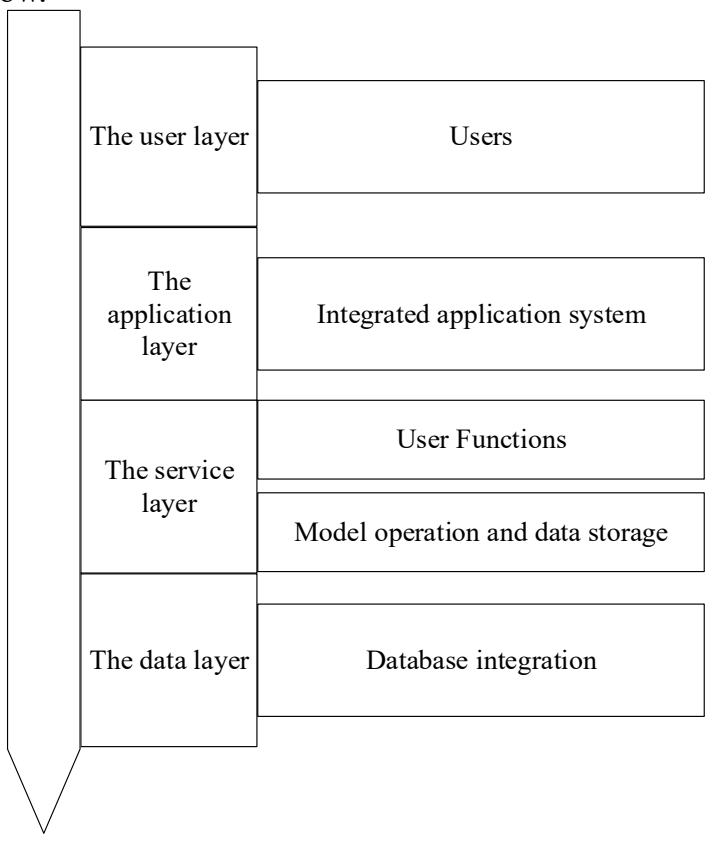

Figure 4 Logical structure diagram of the system

The information-based settlement deformation data query and analysis system includes the functional modules shown in Table 2 below.

Table 2 System Modules and Functions

\begin{tabular}{|c|c|}
\hline The name of the module & Segmentation function \\
\hline Map operation module & $\begin{array}{c}\text { The document, Based } \\
\text { operation, Identify, } \\
\text { Attributes are cross-checked } \\
\text { with graphs }\end{array}$ \\
\hline Data operation module & $\begin{array}{l}\text { Data editor, Data query, Data } \\
\text { conversion, Data load, Data } \\
\text { storage }\end{array}$ \\
\hline \multicolumn{2}{|l|}{$\begin{array}{l}\text { Evaluation and inspection } \\
\text { module }\end{array}$} \\
\hline \multicolumn{2}{|l|}{$\begin{array}{l}\text { Return to zero check } \\
\text { module }\end{array}$} \\
\hline \multicolumn{2}{|l|}{ Draw curve graph module } \\
\hline \multicolumn{2}{|l|}{$\begin{array}{l}\text { Draw the settlement } \\
\text { cumulative value curve } \\
\text { graph module }\end{array}$} \\
\hline Data statistics module & $\begin{array}{c}\text { Statistical, Over-limit data } \\
\text { cumulative statistics }\end{array}$ \\
\hline Data consolidation module & $\begin{array}{l}\text { Auto-add data, Delete some } \\
\text { content, Automatically } \\
\text { deletes non-specified files }\end{array}$ \\
\hline \multicolumn{2}{|l|}{ Query unmeasured points } \\
\hline \multicolumn{2}{|l|}{$\begin{array}{l}\text { Point elevation comparison } \\
\text { module }\end{array}$} \\
\hline $\begin{array}{l}\text { Working base point height } \\
\text { difference } \\
\text { Extraction module }\end{array}$ & \\
\hline
\end{tabular}

\begin{tabular}{|c|c|}
\hline $\begin{array}{c}\text { Settlement fitting coefficient } \\
\text { calculation module }\end{array}$ & \\
\hline $\begin{array}{c}\text { Elevation result table } \\
\text { generation module }\end{array}$ & \\
\hline
\end{tabular}

\subsection{Database Design}

During the construction and operation of high-speed railway, the system database of the system observation and evaluation data information platform contains complicated and diversified data information. Considering the its form, type and function, settlement deformation data is divided into two categories: spatial data and attribute data, which are included into

integrated management of data. The data of this system is mainly taken from engineering data such as monitoring point information and observation records. The data is subdivided into graphic data, statistical data and attribute data. The graphic data is a settlement monitoring distribution map, which has been transformed into vector form. The statistical data is a settlement monitoring data map or data sheet, which is used for the development of database and system. The attribute data is stored in Geodatabase, which is the information to express graphic attributes. There is a huge amount of data which is usually used for the development of database and system. As part of the settlement monitoring data processing procedures, it can display and process the distribution and characteristics of settlement monitoring points. ${ }^{[9]}$.

To build a database, the following data processing steps are required. a. data collection and classification: Considering the complexity and variety of data information, the settlement deformation data that has been collected is classified and stored according to the above-mentioned three data types, namely graphic data, statistical data and attribute data. b. data processing: the data format is converted to ArcGIS. c. Table structure confirmation: by confirming user requirements, appropriate data table structure is constructed, and attribute data is determined. $d$. Data encoding: the data is encoded after the format is unified, so that the encoding of each space is determined and exclusive. e. Data storage: data attributes are extracted and all fields are stored together. f. Data association: encoding makes space correspond to attribute database one by one. Data sources are extensive, diverse, large-scale and multidimensional. Therefore, CAD data model, Coverage model and Geodatabase model are selected ${ }^{[10]}$.

Construction procedures of the database are as shown in Figure 5 below: 


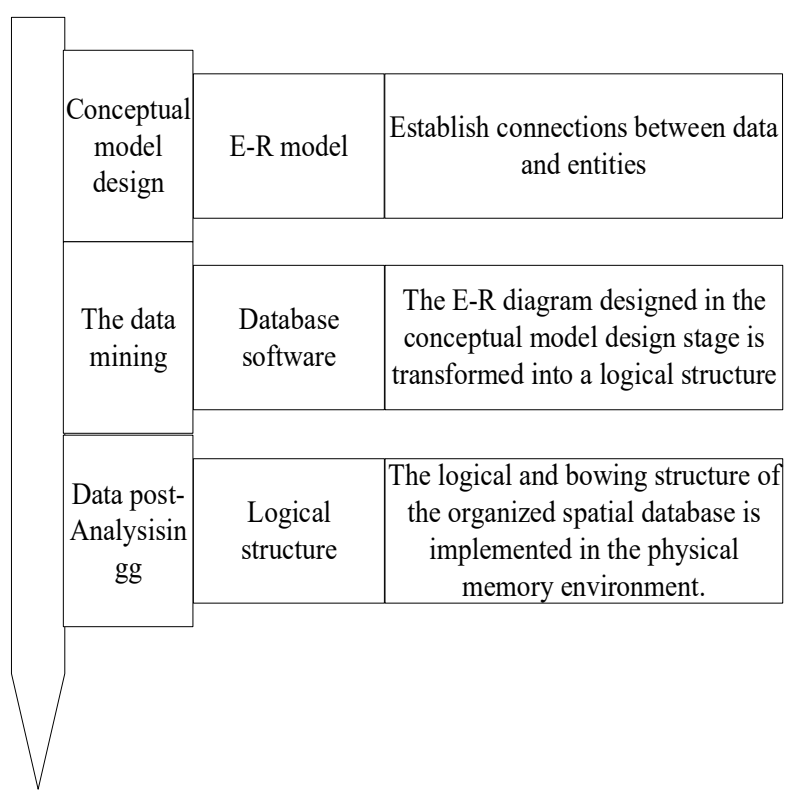

Figure 5 Construction Phase of Database

a. Conceptual model design establishes a one-to-one connection between data and entities to describe the real world within the data.

b. Logical model design: The E-R diagram in the previous stage is transformed into a logical structure, and the entity is described as a spatial data model.

c. Physical model design: The logical structure generated in the previous stage is implemented in the physical memory environment.

Data preprocessing: the projection, scale, coordinate system, format and unit of basic data are unified, and the data is converted into shape format. The attribute data is labeled as important, encoded, and marked with unique identifiers. The scale, projection and coordinate system of graphic data are unified.

\section{Information Platform for settlement deformation observation data}

\subsection{Implementation of Information Platform}

\section{(1) System Implementation}

A. Platform Login: The login system is as shown in Figure 6 below.

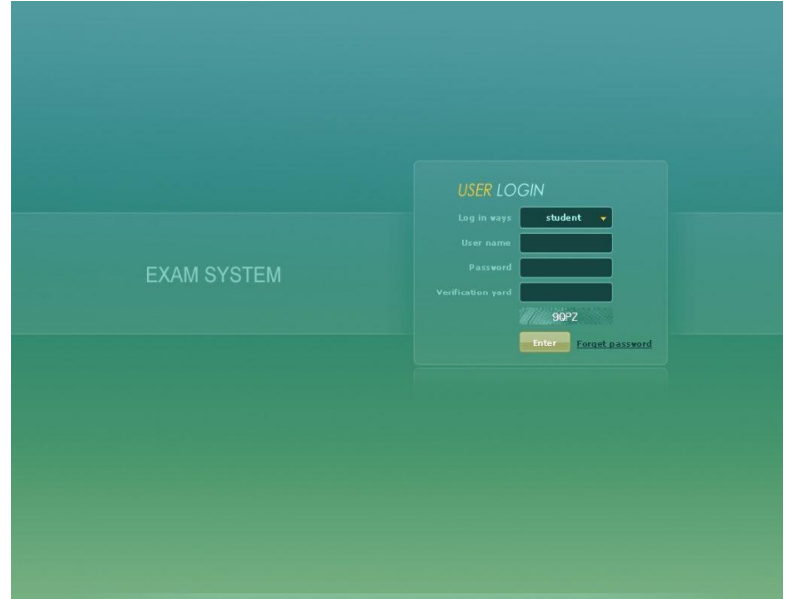

Figure 6 System login screen

The software is set up to ensure the safe operation of the system, and confidentiality of monitoring data, and observe and evaluate the practicability of the information platform system. On the one hand, the user login interface limits the user to $\log$ into the system, which reduces malicious harassment, and can prevent leakage of the obtained monitoring data. When first logging into the system, you are required to use the registered user name and password to enter the platform system for settlement observation and evaluation data acquisition. When the user enters the user name and password, the system will compare the input information with the information stored in the back-end system database. If the authentication is correct, you can enter the system on the homepage and complete the login process.

b. Platform Homepage: After successfully logging in to the platform, you will enter the homepage. The homepage is divided into four modules: layer setting area, data window, function setting area and toolbar. Layer Setting Area: It can keep data in archives, navigate layers, and enable users to easily and quickly manage checkpoint, line and surface data. Data Window: On the one hand, this functional area allows users to view settlement monitoring point information directly. On the other hand, it can be used for the task of importing monitoring tables. Toolbar: It provides many common functions of ArcGIS, such as zooming in, zooming out, panning, identifying, and measuring on the map. This design enables users to easily operate on the maps. Function Setting Area: it covers 14 function buttons, with which you can load data, evaluate and reset the check, create charts, draw graphs, draw cumulative value curve for a certain period of time, query weekly reported data and events, automatically clear project data and check the status of unconfirmed points, conduct elevation comparison, display height changes of working points, fit settlement coefficient, draw elevation result charts, do map test, mutually check maps and attributes, etc. When the function button is used, a corresponding window will pop up, allowing the user to perform corresponding operations and output information such as corresponding parameter settings based on the use of the button. 


\section{(2) Data Query and Storage}

The module can synchronize the stored data with the newly collected data, and then display or output the query results in the form of tables to meet the query needs of users. The system can convert documents between different formats including excel, txt and csv. The platform uses Geodatabase for information storage and query.

\subsection{Observation results of high-speed railway settlement}

The observation results of settlement deformation of high-speed railways are as shown in Figure 7 below.

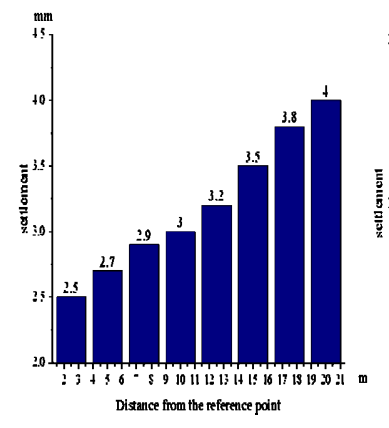

(a)

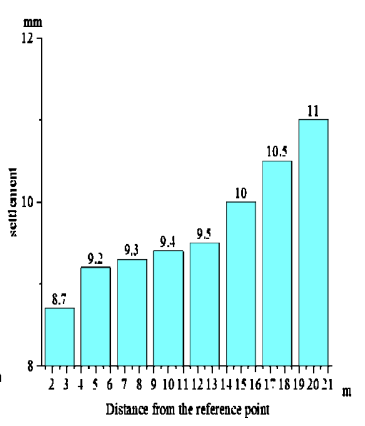

(b)
Figure 7 Observation results of settlement deformation of high-speed railway (a) after completion of filling (b) 6 months after pre-filling

It can be seen from the figure that no matter after landfill or half a year after pre-landfill, the observation result of high-speed railway settlement deformation is that the farther away from the reference point, the greater the settlement of the landfill foundation. The closer to the edge of the foundation, the more the settlement, and the greater the change rate of settlement deformation. The change of settlement amount measured immediately after landfill is $6.2 \mathrm{~mm}$, but the change rate is $24.8 \%$. However, the amount around the foundation edge is 7.0 $\mathrm{mm}$, and the change rate is only $175 \%$. And with the completion and opening of high-speed railway foundation, the foundation settlement increases and the settlement rate decreases.

\section{Conclusions}

In this paper, the settlement deformation of Zhengzhou-Jinan high-speed railway was observed, and the information platform system model of settlement deformation observation data of high-speed railway was established. On the basis of collecting geological exploration data and field investigation, the elevation measurement and settlement observation of subgrade, bridge and station were completed by using advanced electronic measuring equipment. And the information platform is utilized to realize the visualization of settlement. It greatly reduces the probability of settlement accidents and provides a strong guarantee for the construction and operation of high-speed railway in the later period, and is helpful for further research on automatic monitoring and query of settlement deformation of high-speed railway in the future.

Although this research has basically reached the original research goal and obtained some valuable conclusions, due to my limitation of academic accomplishments, there are still many deficiencies in the research. The research conclusions may be limited by the following three factors: (1) The research on the settlement mechanism is insufficient. (2) It fails to further optimize the settlement early warning mechanism of the information platform. This also points out the direction for our future research. In the future, we will mainly focus on the following two aspects: (1) The settlement deformation mechanism of Zhengzhou-Jinan high-speed railway will be further studied. (2) The early warning mechanism of the platform will be further improved to realize timely warning of acute settlement and large amount of settlement.

\section{About the author}

Ni xiuyong (1982 -), male, Han nationality, from Linyi, Shandong Province, master's degree, lecturer grade 8 , research direction: Road and bridge professional course teaching.

\section{Reference}

1. Wang, Liu Yong, Yuan Jiao, et al. Development and application of intelligent monitoring and evaluation system for settlement of high-speed railway. Journal of railway engineering, 2019, 36 (4). PP. 20-25.

2. Khairallah D, Blanc J, Hornych $\mathrm{P}$, et al. Influence of the Bituminous Layer on Temperature and Water Infiltration in Railway Structures of the Bretagne-Pays de la Loire High-Speed Line. Journal of testing and evaluation, 2020, 48(1). pp. 134-149.

3. Park S, Kim J, Kim J, et al. Analysis of Dynamic Characteristics of Deformed Concrete Slab Track on Transition Zone in High-Speed Train Line According to Train Speeds. Applied Sciences, 2020, 10(20). pp. 7174.

4. songxuguo, guoshuaijie, Chen Hongyun. Calculation of settlement of parallel high speed railway based on stress extraction of numerical model. Railway standard design, 2019, 63 (3). PP. 5-11.

5. Li Longkun, guoxuping, tianchunyang, etc. on the application of High-speed Railway Settlement Monitoring in the project of Zhengxu high-speed railway crossing under 107 auxiliary roads. Resource guide, 2019, 1 (4). PP. 32-34

6. Moghadam M. Numerical Analysis of Railways on Soft Soil Under Various Train Speeds. Transportation Infrastructure Geotechnology, 2020, 45(4). pp. 179-191. 
7. Mehrabi N, Khabbaz H. A trustful transition zone for high-speed rail using the stone column technique. Australian Journal of Civil Engineering, 2020, 6(2). pp. 59-67.

8. yaoyangping, Wang Wei, Wang Naidong, et al. Prediction method of long-term settlement of high-speed railway subgrade under the influence of temporary line loading. Journal of geotechnical engineering, 2019, 41 (4). PP. 625-630
9. Li Xuegui. Analysis of settlement observation of the off-line project of the station building of Yinxi high speed railway airport. Encyclopedia forum electronic, 2019, 1 (6). Pp.287.

10. Muhammed J, Jayawickrama P, Teferra A, et al. Settlement of a railway embankment on PVD-improved Karakore soft alluvial soil, 2020, 2(4). pp. 233-251. 